\title{
Fortegnelse over \\ Pastor Carsten Petersens trykte Arbejder.
}

Ved Jens Holdt.

Carsten Petersens Pen hører til de ædleste i vor sønderjydske Hjemstavn. En grundig historisk Viden, en øvet Tænkeevne og en kunstnerisk Formsans præger hans ret omfattende Forfatterskab, der utvivlsomt vil blive staaende $\mathbf{i}$ den danske Litteratur fra Grænselandet. Han følte sig altid som dansk Slesviger og var een af Redaktør Jens Jessens varme Beundrere. Som Præst $i$ det nationalt blandede Grænseland afholdt han sig dog fra enhver aktiv Deltagelse $i$ den folkelige Kamp og koncentrerede til Gengæld sin personlige Indsats i Tale og Skrift omkring det aktuelt kirkelige og efterhaanden mere og mere det kirkehistoriske Stof. Hans Arbejde sigtede ufravendt paa en kristelig Vækkelse og Oplysning af Landsmænd, der derigennem indirekte ogsaa fik en væsentlig, maaske afgørende Støtte i Hævdełsen af deres danske Menneskelighed. Dannelsen af Kirkeligt Lægforbund i 1913 støtter sig saaledes vist $i$ væsentlig Grad til hans Synspunkter. I Sammenhæng med sin nordiske Indstilling blev det naturligvis Nord fra, Carsten Petersen hentede Emnerne for sine litterære Frembringelser. Det var den danske Kulturarv, han udmøntede for sine slesvigske Landsmænd - vel ogsaa som en tiltrængt Modvægt mod de fleste af hans Præstekollegaer, der var ivrige efter at sprede tyske Kulturtraditioner i det folkeligt endnu ikke erobrede danske Nordslesvig.

Som ung Præst i Brarup i Mellemslesvig (1903-11) syslede Carsten Petersen med en videnskabelig Afhandling om Søren Kierkegaard og fandt samtidig $\mathrm{i}$ denne store religiøse Tænkers Syn sit eget aandelige Stade. I disse Gæringsaar blev han knyttet som Medarbejder til det førende tyske Kirkeblad i Provinsen, hvor hans kirkehistoriske og arkæologiske Interesse og hans personlige Forbindelse Nord paa blev taget i stigende Brug. Men 
samtidig begyndte han med at offentliggøre sine lødige kirkehistoriske Artikler og Opbyggelsesstykker i Flensborg Avis' Søndagsblad og i den indremissionske Almanak for Nordslesvig. Da han i 1911 forflyttedes til Magstrup ved Haderslev - efter at han paa Grund af sit danske Sindelag var "dumpet« som Provst i Tønder - fik han her straks et naturligt og paaskønnet Medarbejderskab ved Pastor Tonnesens indremissionske Ugeblad "Sædekornet«, fortrinsvis $\mathrm{i}$ de afgørende Aar 1911-12, og siden ved Bevægelsens Ungdomsblad og Børneblad, hvis Redaktørposter han overtog.

Verdenskrigens Smerteaar 1914-18 gav Genforeningshaabet ny akut Styrke, hvilket for Carsten Petersens Vedkommende fik et sjældent fint og stærkt Udtryk i hans i disse Venteaar skrevne Digtsamling "Mit Land", skabt ud af et følsomt dansk Grænselandssind, der helst saa hele det gamle danske Land vende tilbage til Moderlandet. Studerer man Overskrifterne til hans opbyggelige Stykker i "Kristeligt Ungdomsblad" fra disse Aar, lyser ogsaa ud af disse Forventningen om det sønderjydske Folkehaabs snarlige Opfyldelse ved Krigens Afslutning. Den forestaaende nye Grænsedragning lod ham i Overgangstiden tage stærkt til Orde (først i Flensborg Avis og siden i Kristeligt Dagblad) for en ren kirkelig (og ikke blot politisk) Ordning af det genvundne Lands kirkelige Forhold. Han saa helst det kirkelige Selvstyre (Synodalforfatningen) fra den tyske Tid bevaret og udbygget, idet han vilde lægge "Magten« $i$ det vaagne og villende Kirkefolks egen Haand. Det havde været naturligt og var ogsaa i høj Grad ønsket, at Carsten Petersen havde faaet Sæde i det af Vælgerforeningen nedsatte kirkelige Udvalg, der i Vinteren 1918-19 arbejdede med Forslag til Nyordningen af de sønderjydske Kirkeforhold. Men han ønskede ikke at modtage et kirkeligt Mandat af en politisk Myndigheds Haand - det havde man bestandig modsat sig i tysk Tid, hævdede han - og afslog derfor trods gentagne Opfordringer og Forhandlinger ud af en vis "Stædighed" at indtræde i det arbejdende Udvalg, som naturlig- 
vis bestod af Kirkens udvalgte Mænd. Han var iøvrigt jo ogsaa Modstander af den aabenraaske Grænsepolitik. I samme Anledning fældede han til Gengæld sagligt skarpe Domme over de tysksindede nordslesvigske Præsters kirkelige Svigten, især under Krigsaarenes højtstemte Nationalisme. Han mente, at de fleste af dem efter deres brudte Tillidsforhold overfor deres Menigheders dansksindede Medlemmer vanskeligt med god Samvittighed kunde fortsætte efter Genforeningen, medens der naturligvis skulde ydes dem fuld personlig Retfærdighed. De herom anonymt offentliggjorte Artikler i Kristeligt Dagblad vakte voldsom Harme i tyske Præstekredse, der beskyldte Forfatteren for Dolkestød i Ryggen. Det kom bl. a. til et stormende Opgør paa et Møde i Vojens i Julehelgen 1920, hvor man paa ingen Maade vilde gaa med til at nominere ham som deres Repræsentant $i$ det store kirkelige Landsudvalg af 1921 til Forberedelse af den kirkelige Genforeningslovgivning. Han valgtes da af Lægfolket. Til retfærdig Bedømmelse af Situationen maa dog bemærkes, at der jævnsides med Carsten Petersens PræsteArtikler i Kristeligt Dagblad stod nogle andre, betydeligt skrappere Indlæg om samme Emne, ogsaa anonyme, formodentlig skrevne af Pastor H. I. F. C. Matthiesen i Vamdrup, Bladets forhenværende Redaktor og en vaagen Iagttager af Forholdene sønden Aa. Han var jo selv af sønderjydsk Slægt og blev efter Genforeningen Præst ved Domkirken i Haderslev. Carsten Petersen maatte vist bære Modviljen overfor begge Artikelrækker.

Efter 1920, da Carsten Petersen atter blev forbigaaet som Provsteemne (nu var han vel for slesvigsk sindet), trak han sig mere og mere tilbage fra Deltagelse i den kirkelige Døgnjournalistik og traadte i Stedet "de dødes Spor", viede nu sin Tid og sine Kræfter - især som tidlig Emeritus - til ofte møjsommelige kirkehistoriske Arkivstudier, hvis Resultater siden offentliggjordes i Sønderjydske Aarbøger og i det store særprægede Værk "Slesvigske Præster«. En Del utrykt Stof er deponeret i Arkiv. 
Der kan paa Grund af Forfatterskabets store Spredthed i tyske og danske Blade og Tidsskrifter ikke garanteres for Fuldstændighed i den her fremlagte Fortegnelse. Men det væsentligste turde være fundet frem, det meste fra private Ejeres Gemmer. Oversigten er i Hovedsagen ordnet kronologisk. Dog er de enkelte Gruppers Arbejder alle samlede under samme Nummer. Alle Aarstallene er satte med fed Type, Side- og. Datumtallene derefter med almindelig. Meddelelse om evt. glemte Ting imødeses gerne.

1. K i r c h e n- u n d S ch u l b lat t [det konservative Kirkeblad i Slesvig-Holsten-Lauenborg]:

Kirchliche Bewegung in Kopenhagen [Referat fra en Rejse til Kabenhavn, 1905, 517-21; 529-32. [ogsaa trykt i H a m b u r g is c h es Ki r chen b l a t t, 1905, 389-93, hvis Udgiver, Pastor K. Reimers ved St. Michaelis Kirke i Hamborg, rejste sammen med Forf.].

Protestantischer Kirchenbau [Referat fra Deltagelse i 2. Kongress für Kirchenbau i Dresden], 1906, 511-17. - Boganmeldelser, 393-95; 405-06; 612-13.-

Rückblick auf das Jahr 1906, 1907, 6-9; 13--15; 25-31; 35—11. - Das Jahresfest in Brecklum [Referat], 312-15. -

Rückblick auf das Jahr 1907, 1908, 17-20; 25-30; 37-40, 49-51. - Boganmeldelser, 218-19; 639-40. - Rückblicke in das vergangene Vierteljahr [ved Spectator = Carsten Petersen], 384-87; 389-96. — Hamburg, 542-46. — Rückblicke, 572-74; 581-86. - Das System des Missverständnisses [Indlæg i Debat om Generalsuperintendent Th. Kaftans Teologi i Anledning af dennes Bog "Der Mittler"], 510-12. -

Rückblicke, 1909, 73—77; 89-96;325-29;333-38. - Der Dom von Schleswig [Beskrivelse], 111-15; 126-30. - Als der Tag der Pfingsten erfüllet war, 301-03. - Die Bedeutung des kirchlichen Zusammenhangs für das geistliche Leben der einzelnen Seele [Teser til Indledningsforedrag ved Lutherische Konferenz 
paa Diakonissestiftelsen i Flensborg 28.-29. 4. 1909, 253-56. Særtryk: Die Bedeutung des lutherischen Bekenntnisses für unsere Landeskirche [Teser ved samme Konvent 20.-21. 10. 1909]. - Ueber die Lockerung des Parochialbandes. Aus dem Vortrag "Verfassungsfragen in der lutherischen Kirche Dänemarks« [ved Lehrkonferenz i Mölln, Lauenborg, 8.-9. 9. 1909], $521-26 ; 529-33$. [ogsaa trykt i Hannoversche Pasto$x$ a l-K o n f e r e n z 1909, 353-57; 369-72.] —

Die Mitwirkung der Geistlichkeit bei der Denkmalpflege, 1914, 60-62; 71-72. - Rasmus Nielsen [Anmeldelse af E. Asmussens Doctordissertation: Entwicklungsgang und Grundproblem der Philosophie Rasmus Nielsens], 307-10, -

2. Ge meindeblatt für das Kirchspiel Braderup [udgivet af Landesverein für Innere Mission i Slesvig-Holsten, sidste Side redigeret af Sognepræsten, kun enkelte Eksemplarer fra 1909 bevarede]:

Af Sognets Præstehistorie; Rejsebrev fra 'Trollhättan [bl. a. om det rige Gudstjenesteliv i København].

3. Evangelische Kirchen-Zeitung. [grundlagt af E. Hengstenberg, redigeret af Pastor Pauli, Friedersdorf ved Seelow]:

Søren Kierkegaard, 1911, 193-97; 209-12; 226-29; 245-48. -

4. Volkska le nder [udgivet fra Breklum]: Materialismus [Aargang ikke kendt].

5. I J e s u Fod s p o r. Et Guds Ord til hver Dag, udlagt af nordslesvigske Præster, 1906, 52-58; 362-71 [udgivet af Præsterne C. Matthiesen, Rødding, og Chr. Petersen, Skodborg]. -

6. Nordslesvigsk Søndagsblad [Følgeblad til Flensborg Avis]:

Om Slægten Zoëga i Nordslesvig, 1907, 153--56; 161-64; 169-72. Dejlig er den Himmel blaa, 401-03. -

Pest. Nogle Træk af vore Forfædres Lidelseshistorie, 1908, 161 
$-($ i5; $169-71 ; 177-80 ; 185-88$ [efter Dr. F. V. Mansa: Folkesygdommenes og Sundhedsplejens Historie i Danmark]. Hans Egede, 329-31; 337-40. -

Hans Adolf Brorson, 1909, 353-56; 361-65; 369—73. Dejlig er Jorden, 409-11. -

Søren Kierkegaard, 1910, 193-95; 201-03; 209-12; 217-20; 225-28; 232—36; 241-43; 249-51. Uddrag af Søren Kierkegaard: Hvad vi lære af Liljerne paa Marken og af Himlens Fugle, 257C2; 265-67; 273-75. Da det blev Jul paa Jorden, 209-11. En gammel Spaadom, 1912, 153-55 [om Guldhornene efter Vaticinium de infundatione Holsatie]. Glade Jul, 401-03. Johannes Ewald og hans Slægt, 1913, 105-07; 113-16; 121-23; 129-32; 137-38; 145-46. Sankt Nikolavs, 401-03. -

Domkirkerne i Slesvig og Ribe, 1915, 321-24; 329-31; 337-40, 34う̌-48. Kærlighed, 401-03. -

Profeten, 1. Profeten og Fortiden; 2. Profeten og Fremtiden. 3. Profeten og Smerten [Nutiden], 1916, 345-47;349-56;361-64. I dit Lys skal vi se Lys, 1917, 401-03. -

Danske Salmer i Oversættelse. Endnu noget om Brorsons Julesalmer, 1927, 21-22. -

7. Kristelig Folkekalenderfor Nordslesvig [udgivet fra Breklum]:

Foraarsarbejdet, 1909, 59-61.

Salt, 1912, 49-63. -

Hertug Kristian paa Haderslev Hus, 1913, 43-69. -

8. Indre Missions Almanak [udgivet af TonnesenFlojen efter Bruddet i 1912]:

Ild er jeg kommen for at kaste paa Jorden, 1914, 65-71.

Gudstjenesten, 1915, 8-25 [en historisk Oversigt]. -

9. Rejsemaaltid. En meget kort Andagtsbog for Ungdommen, 1911. Haderslev, 92 Sider.

10. Sæd e k or net [indremissionsk Ugeblad for Nordsles- 
vig, udgivet og redigeret af Pastor $H$. Tonnesen i Hoptrup]: Tanker fra Reformationssøndagen. Forvisningen, 1904, Nr. 47; 6-7. -

Optryk af et Stykke fra "Rejsemaaltid", 1911, 64-65. Kostbart Legetøj, 295-97. En Time - kun een, 297-98. Aanden og Kødet, 341-43. Et Menneskeliv, 355-56. Autoritet, 413-15. Din Forretning, 468-69. Gamle og nye Samfund, 490-92. Boganmeldelse af J. Brandtzæg: Livets Vej, 595-06. Sig Sandheden, 547-49. Du skal ikke begære, 577-78. Da Menigheden sang, 599-600. Jeg og du og vi, 633-35. Vejen til Lykken, 635-36. Fanen, 648-50. -

Kirkelige Nutidsspørgsmaal. Frit Ordskifte. Redigeret af Pastor Petersen, Maugstrup, 1912, 93-94. „Opraab til Menighederne" fra 245 slesvig-holstenske Præster, 129-30. En gammeldags Konfirmation, 137-38. "Selvbeskatningen", 152-54. Langfredag, 165 [Optryk fra "Rejsemaaltid«]. At tro - at tro ret, 219-20. Kristelig Verdensanskuelse, 246-48. Jeg tror, at Gud har skabt mig, 248-49. Lægprædikanters Adgang til Prædikestolen, 258; 284-85. Nogle Spørgsmaal angaaende det sociale Arbejde, 276. Kaster eders Garn ud til en Dræt, 313-15. Studiekredse, 406. Jesus Kristus, Guds Søn, 458-59. Jesus Kristus, Marias Søn, 460-61. I Guds Stad. Matth. 9, 1-8; 481-83. De venter alle paa dig. Sal. 104, 27-31; 483-85. Som et Eventyr. Matth. 22, 1-14; 493-95. Han troede selv og hans ganske Hus. Joh. 4, 46-53; 505-07. Eet Sind, 578-80. -

En Søndag i London. [Rejseskildring], 1913, 363-67. KKina Indlands Mission, 416-20. Magter og Riger [Besøg i British Museum], 423-27. Har Haand du lagt paa Herrens Plov, da se dig ej tilbage. Luk. 9, 61-62 [Tale ved Indre Missions Aarsfest 20.10.1913], 529-32. -

Bibelen, 1. Bibelunderet, 1914, 73-75. 2. Min Bibel, 85-87. 3. Bibelens Bogstav, 97-100. 4. Bibelens Læser, 109-111. 5. En lille Prædiken, 121-22. 6. Bibelen i det Fremmede, 133-36. Billeder [A nbefaling af bibelske Billedbøger], 144. Isak, 211-13. 
11. Kristelig t Ung dom s b la d [udgivet af Fællesforbundet for de kristelige Ungdomsforeninger i Nordslesvig, fra 1914-19 redigeret af Carsten Petersen]:

Om Karakterdannelse hos de Unge, 1912, 11-14 [Foredrag ved Fællesforbundets Lederkursus 24.-25. 1. 1912]. -

K. F. U. M.'s Verdenskonference [i Edinburgh], 1913, 51-54; 6063; 67-70; 75-79. - Tanker fra Edinburgh. Foredrag ved Aarsfesten i Vojens [2. 11.], 91-93. -

En Herre, rig nok for alle dem, som paakalder ham. Rom. 10, 12-13, 1914, 26-27. Korset. 1. Kor. 1, 18, 57-58. Oxford, 67-69; 75-76; 83-85. At prøve og vælge. Fil. 1, 10, 65-66. Hunger, Mt. 5,6, 73-74. Advent. Rom. 14, 17, 89-90. -

Herren er mit Banner. 2. Mos. 17,15, 1915, 2. Omvendelse. Ap. Gern. 11,21, 4-5. Et kort Navn. Ef. 1,1, 9-10. Vore Drenges Forhold til Kristus, 11-13. - 108 onde Aander. Luk. 13,32, 17--18. Drengens Plads i K. F. U. M., 19 21. Svinghjulet. 1. I Livet. Mt. 17, 18-20 [Troen], 26-27. 2. I Døden. Ap. Gern. 2,26 [Haabet], 33-35. 3. I Evigheden. 1. Kor. 13,13 [Kærligheden], 41-43. Sure Druer og ømme Tænder. 1. Fædrene. Jer. 31,29; 49-51. 2. Børnene. Jer. 31,50; 75-79. Fra Rejsen [til Nyborg-Mødet 7. 6.], 6264. [Numret mangler], 65-? ?. Hvert Hoved er sygt og hvert Hjerte er mat. Es. 1, 4-5; 73-75. Allesjæles Dag. Aab. 1,18 [Prædiken i Maugstrup Kirke 2. 11.], 81-84. Lader os gaa i Rette med hinanden. Es. 1, 18, 89-90. -

Gud i Himlen, han skal lade det lykkes for os. Neh. 2, 17-20, 1916, 2-4. "Denne Tid«. Luk. 12,54 [Slutningsforedrag ved de Unges Kursus i Haderslev], 11-13; 19-21. Ting, der rystes, og Ting, der ikke rystes. Hebr. 12,27; 34-35. Pinse, Joh. 3,16; 42-43. Drengen [Digt; Feltnummer], 50-51. Enten vi lever eller vi dør, er vi Herrens [Tale over en tolvaars Pige, som døde ved et Vaadeskud fra sin Broders Haand], 57. Skulde vi da ikke vente Es. 64, 2-3, 61-63.*) De skjulte og de aabenbare Ting. 5. Mos.

*) Optrykt i Haderslev Stifts Aarbog, 1946, 12-14. 
29,29; 78-80. Gammel Visdom [Besøg paa Flensborg Kunstindustrimuseum], 86-87. -

Herren vender Forbandelse til Velsignelse. 5. Mos. 23,5, 1917, 1-3. Lyde og tro. 2. Tess. 3,4; 17-18. Det er mig godt, at Gud er mig nær. Ps. 73,28; 25-27. Himmelfartsmøderne [Beretning fra Haderslev, Dybbøl og Gram], 45-47. Mange Vandes Lyd. Aab. 1,16, 53-55. Feltbreve [til J. Kylling, J. Børsen-Hansen og Anton Hansen], 58-63. Sejr og Liv. Aab. 2,7, 66-67. Gud maa være sanddru, om end hvert Menneske er en Løgner. Rom. 3,4, 77-78. Tre Grundpiller i M. Luthers Trosliv. Rom. 3, 23-26; 89-91. Af Menneskets Historie, 1. Mennesket skabt i Guds Billede. 1. Mos. 1,27; 101-04. 2. Sjæl og Legeme. 1. Mos. 2,7; $113-16$.

3. Mand og Kvinde. 1. Mos. 2,18-25, 1918, 9-12. 4. Det første Fald. 1. Mos. 3, 1-13, 17-19. 5. Forbandelse og Forjættelse. 1. Mos. 3, 14-24, 25-29. I Jesu Navn. Mt. 1,21, 2-4. Til K. F. U. K. [om Ansættelse af en kvindelig Rejsesekretær], 32. Himmelfart. Ps. 110,3, 33-35. Han, som elskede først. 1. Joh. 4,10, 49-50. Salig er den, som holder Maaltid i Guds Rige. Luk. 14,15, 57-59. Jesus sejrer. Es. 53,11-12, 65-66. Udvælgelsen. Rom. 9,18, 73-76. Fred og Sandhed. Jer. 33,6, 1919, 1-3. Besøg paa Diakonissestiftelsen i København. - I Guds Navn. 1. Sam. 17,45. - Arbejdet. Kristi Himmelfartsdag 1919. - Meddelelser fra Fællesforbundet, $2-4 ; 5-8 .-$

12. Børnenes Søndagsblad [udgivet af Indre Mission i Nordslesvig 1911-19, redigeret af Carsten Petersen 191316, kun enkelte Eksemplarer bevarede]:

Langfredag, 1911, 29 [optrykt efter "Rejsemaaltid«] Mit første Møde med Bibelen, 95. - Min Moder og jeg, 102-06 [Julenumret] -

En Drøm [Fredsdigt til Billede af M. Antokolski's Vejkors "PAX«], 1915, 112. - 
13. R e f ormation en [Særtryk af Foredrag paa Haderslev Provstisynode 19. 7. 1917]. 8 Sider. -

14. A ll e S j æ l e S D a g, 1918 [med Fortegnelse over Maugstrup Sogns faldne i Krigen 1914-18]. 8 Sider. -

15. M it L a nd, 1919 [en Digtsamling med Motiver fra Sønderjyllands Landskab og Historie til Verdenskrigens Slut, iflettet personlige Minder]. 142 Sider. -

16. F l ensborg Avis:

Slesvig [Mint Slesvig do æ dog den Plet, æ skal hold a], 1892, 19.1. Sorgen [i Anledning af Drukneulykken paa Brede Aa 14. 6. 1912], 1912, 16. 6. -

Folkekirken i Nord og Mellemslesvig, 1918, 14.12. En fri Folkekirke, 16.12. Vor Opgave, 18.12. Kirkens Selvstændighed, 19.12. Den nye Jul, 24.12. Folkekirken, 30.12. -

17. K r is t e lig t D a g b lad [signeret: Fra vor kirkelige Medarbejder i Sønderjylland, hhv. Privatkorrespondent, hhv. Carsten Petersen]:

Præsten i Nordslesvig, 1919, 14.1. Overgangen, 16.1. De første Haandslag [Besøg af 'K. F. U. M.- og K.-Ledere fra Danmark ved Lederkursus i Haderslev], 6.2. De nordslesvigske Synoder, 1. Provstisynoderne, 10.3. 2. Fællessynoden, 13.3. 3. Et Ord til Bedømmelse af deres Værdi, 14.3. Skillelinjen [i Anledning af "Det gamle Budskabs Indre Mission«s Fortsættelse i Nordslesvig], 19.3. De slesvigske Præster, 25.3.; 26.3. Skal Folkekirken have Lov til at tale selv? 27.3. En Bøn til dem, der vil tale Guds Ord i Nordslesvig [om at lægge Vægten paa det kristelige i Stedet for det nationale], 31.3. Næste Aarsmøde i Slesvig [om ikke at haste for meget, men tage det sindigt] 22.9. Lægmanden i Nordslesvig, 30.3. Præsterne og Skolen i Nordslesvig [om Afskaffelsen af Præsternes Skoletilsyn], 3.10. "Det gamle Budskabs indre Mission i Nordslesvig" [i Anledning af dennes Henvendelse til I. M. i Danmark om Optagelse], 3.11. - 
Den nordslesvigske Salmebog [foreslaar Indførelse af den kongerigske med sønderjydsk Tillæg], 1920, 2.3. Den danske Kirke i Slesvig [Genforeningsnummer], 9.7. -

Tilsynet med Folkeskolen [tilfreds med den nỵe Ordning], 1921, 5.12. -

18. Præs teforeningens B lad:

Vidnesbyrdet i Forkyndelsen. Tale ved Præstekonvent paa $\mathrm{Ny}$ borg Strand, 1923, 281-85. -

19. P e der J. W a n d a l. Et Præsteliv i det syttende Aarhundrede [i Maugstrup 1627—59], 1924, 131 Sider. -

20. Dansk Kirkeliv, medens Tiderne skifter [redigeret af Johs. Nordentoft]:

Efter fem Aar. Fra Kirkelivet i Sønderjylland, 1925, 45-64. -

21. Prædiken: Han, som kommer [udsendt af Kristeligt Pressebureau til 1. Søndag i Advent], 1926, trykt bl. a. i "Hejmdal« 26.11. 1926. -

22. Sønderjydske A arbøger [udgivet af Historisk Samfund for Sønderjylland]:

Landsbykirkerne i Haderslev Provsti efter Reformationen, 1931, 234-71. -

Søren Kierkegaard og Nordslesvig, 1933, 1-38. -

Kirker i Tørninglen Provsti, 1939, 188-231 [belønnet med Dansk historisk Fællesforenings Pris; se Sønderj. Aarb. 1941, 169]. Kirker i Tønder Provsti, 1941, 1-52. Kirker i Aabenraa Provsti, 171-203. -

Wirker i Sønderborg Provsti, 1942, 161-99. -

Slesvigske Præstegaarde, 1946, 231-98. -

23. Slesvigske Præster. Et Udsnit af Præstestandens Historie, 1938, 369 Sider.

24. Haderslev Samfundets Aarsskrift:

Da vi gamle gik i Skole, 1940, 5-18. - 
25. Sønderjy d sk Maanedsskrift [udgivet af Historisk Samfund for Sønderjylland]:

Anna Ludvigsen, f. Lauterup, 1940, 141-46. -

Fra Landudskiftningen paa Als, 1941, 56-61. -

I Skoven grunder den gamle Eg, 1947, 141 [optrykt Lejlighedssang fra 1898].

26. Slesvigske Landsbykirker gennem 300 Aar, 1941, 215 Sider [Særtryk af Artiklerne i Sønderj. Aarb. 1931-41]. -

27. Det $s ø n d e r j y d s k e$ Forslag til Den danske S a $1 \mathrm{~m}$ e b o g. Et Forarbejde, 1943:

Nr. 668: Sænk din Fred, vor Gud og Fader [1936; skrevet til Indvielsen af Vojens Kirkegaard]. Nr. 913: Da Moses gik alene op [1936].

28. Lejlighedssange :

Ved P. A. Sørensen og Anne Kj., født Hansen's Guldbryllup i GalJehus 21.10. 1898: Det er saa yndigt at følges ad. - Langt, langt fra Storhedshigen. - I Skoven grunder den gamle Eg.

Slægtens Gang og Slægtens Sang [ved Familiefest i Gallehus 15.6. 1931]: Vi fødtes i en vejrbidt Hytte. - Syng, Broder min, nu Sangen om vor Moder. -

Gallehus [ved Familiefest i Møgeltønder 1936]: Ve en Dam mæ lidt Siv o en Skov mæ lidt Ly. -

Kækt og stærkt, varmt og blødt [ved pens. Degn og Lærer J. H. Jensen's 90 Aars Fødselsdag i Møgeltønder 28.10. 1936, død 18.5. 1939]. - 